\title{
COMPARING METHODS FOR COMPUTING THE TIME OF CONCENTRATION IN A MEDIUM-SIZED HUNGARIAN CATCHMENT
}

\author{
E. D. NAGY ${ }^{1}$, P. TORMA ${ }^{2 *}, \mathrm{~K} . \mathrm{BENE}^{3}$
}

\section{Abstract}

One of the most often-used parameters that describes morphology and runoff from a watershed is the time of concentration (TC). At gauged watersheds, Tc can be determined using rainfall and a runoff hydrograph, while for ungauged watersheds, empirical equations are used. A good initial estimate of Tc greatly improves the accuracy of runoff predictions. In our study, we applied 14 empirical equations to determine Tc. Tarján Creek, which is Iocated in northeastern Hungary, was selected as the trial gauged watershed. It is located in a mountainous region with an area of $72 \mathrm{~km}^{2}$. The input parameters for the empirical equations were determined using geoinformatical tools. To evaluate the accuracy of the empirical equations, HEC-HMS was used to model the runoff. Using the measured runoff data, both continuous and event-based models were calibrated. For direct runoff, Clark's unit hydrograph was selected. Tc is one of the input parameters for this model. After the calibration, the estimates from the empirical equations for TC were compared to the HEC-HMS calibrated values for each subwatershed. The empirical estimates varied greatly. The Wisnovszky-equation, which is most often used in Hunga$r y$, underestimated $T c$.
Address

1 Msc Student, Budapest University of Technology and Economics, eszternagy93@gmail.com

2 Assistant Professor, Budapest University of Technology and Economics, torma.peter@epito.bme.hu;

3 Associate Professor, Széchenyi István University, benekati@sze.hu

* Corresponding author: torma.peter@epito.bme.hu

Key words

- Time of concentration,

- Rainfall-runoff modelling,

- HEC - HMS

- Event-based model.

\section{INTRODUCTION}

Water management projects in small and medium watersheds require the estimation of runoff characteristics. Determination of peak flows and water levels at the point of interest are often adequate measures; however, when a comprehensive study of flood routing and reservoir modelling is required, design hydrographs with different return periods have to be calculated. Often, calibrated hydrographs are not available; instead, synthetic ones are used. The development of a synthetic hydrograph requires the time-response characteristics of the runoff process. Time parameters describe the accumulation of excess rainfall over a watershed and, as such, they have a direct and significant impact on the peak discharge and shape of the hydrograph.
Time parameters are linked to the physical characteristics and the morphology of the watershed. The most widely used parameter for runoff analysis is the time of concentration $\left(T_{c}\right) . T_{c}$ is the time taken by a water parcel to arrive at an outlet from the most hydraulically distant point of a catchment (Grimaldi et al. 2012, McCuen 2009, Fang et al. 2005).

The time of concentration can be defined in six other ways (Grimaldi, et al., 2012) by considering the elapsed time between the different occurrences of the excess rainfall and the runoff hydrograph. All these definitions make it difficult to establish a unique method to estimate $T$. Additionally, very little direct measured data is available. In practice, $T_{c}$ is usually determined by empirical equations. Several studies, such as Grimaldi et al. (2012), McCuen et al. (1984), Fang et 
al. (2007), and Soroosh and Seyed (2011), compared the estimated $T$ for several watersheds. They concluded that there is a large variability between methods to estimate $T_{c}$, and that relatively large errors can be expected in design discharges from those estimates.

In this study we have tested and analysed 14 empirical equations for $T_{c}$ on a medium-sized catchment in Hungary.

To evaluate these methods, a HEC-HMS lumped numerical model was developed, calibrated and validated. HEC HMS has been successfully adapted to Hungarian catchments several times (Bene et al. 2015, Torma et al. 2014, Koch and Bene 2013). The calibrated $T$ values of each subwatershed were compared to the calculated empirical $T_{c}$ values.

\section{STUDY SITE AND DATA}

The Tarján watershed is located in the north Hungarian mountains near the Slovak border (Figure 1). The town of Salgótarján is located in the middle of the watershed. The full catchment size is nearly $90 \mathrm{~km}^{2}$, and the Tarján creek is a tributary of the Zagyva River. The geological region contains volcanic bedrock and mostly forest soils. The average precipitation in this area varies between $550-600$ $\mathrm{mm} /$ year. The elevation changes from 643 meters at the upstream of the watershed to 186 meters above sea level close to the outlet of the watershed. The northern part of the watershed is quite steep and gradually changes downstream, where it transitions into flat land near Salgótarján. A reservoir located near the outlet has the primary function of flood peak reduction with a secondary function of sediment retardation. The capacity of the reservoir is $350,000 \mathrm{~m}^{3}$ at its normal operating level and $2,667,000 \mathrm{~m}^{3}$ at the maximum level.

The following data were obtained from the local water directorate for the study period 2008 to 2010: (i) hourly rainfall measurements near the stream flow gauge; (ii) hourly stream flow measurements $1 \mathrm{~km}$ downstream from the reservoir; and (iii) hourly reservoir elevation measurements. The rating curve of the reservoir (stage-storage) was available as well. We note here that the availability of only one rainfall station is not favourable, but the subsequently presented modelling results suggest that the rainfall provided by this station is representative enough for the whole watershed.

\subsection{Watershed model}

The digital elevation model (DEM) from the GMES RDA project (EU-DEM) was used for the watershed's delineation. This is a digital surface model representing the first surface as illuminated by the sensors; its resolution is 25 by $25 \mathrm{~m}$. The ArcGIS Arc Hydro toolbox and the additional HEC-GeoHMS were used to create the watershed model and derive its morphological characteristics. The resulting streamflow network was compared to the present network, which was digitized from a topographic map. In order to determine the flow accumulation map, the depressions on the DEM were filled, and eight flow directions were distinguished from each cell.

Tab. 1: Watershed parameters

\begin{tabular}{c|ccccccc}
\hline Watershed & $\begin{array}{c}L \\
{[\mathrm{~m}]}\end{array}$ & $\begin{array}{c}S \\
{[\%]}\end{array}$ & $\begin{array}{c}L_{c} \\
{[\mathrm{~m}]}\end{array}$ & $\begin{array}{c}S_{c} \\
{[\%]}\end{array}$ & $\begin{array}{c}A \\
{\left[\mathrm{~km}^{2}\right]}\end{array}$ & $\begin{array}{c}D \\
{[\mathrm{~m}]}\end{array}$ & $\begin{array}{c}H \\
{[\mathrm{~m}]}\end{array}$ \\
\hline W1 & 4700 & 5.96 & 2384 & 1.34 & 9.82 & 1768 & 359 \\
W2 & 6871 & 3.86 & 5384 & 1.13 & 18.19 & 2406 & 263 \\
W3 & 11935 & 2.97 & 9892 & 1.18 & 34.29 & 3304 & 360 \\
W4 & 6811 & 1.25 & 5270 & 0.63 & 10.08 & 1791 & 150 \\
\hline
\end{tabular}

Notation: $L$ - maximum distance between the outlet and divide, $S$ - mean basin slope, $L_{c}$ - length of the main channel, $S_{c}$ - slope of the longest channel, $A-$ area, $D$ - equivalent diameter of the watershed $(D=\sqrt{4 A / \pi}), H$ - difference in elevation between the outlet and divide.

The watershed was divided into six subwatersheds, four of which (W1-W4) are upstream of the gauge station. Eight stream reaches were set up based on observations from the field reconnaissance. The main morphological characteristics are presented in Table 1. In order
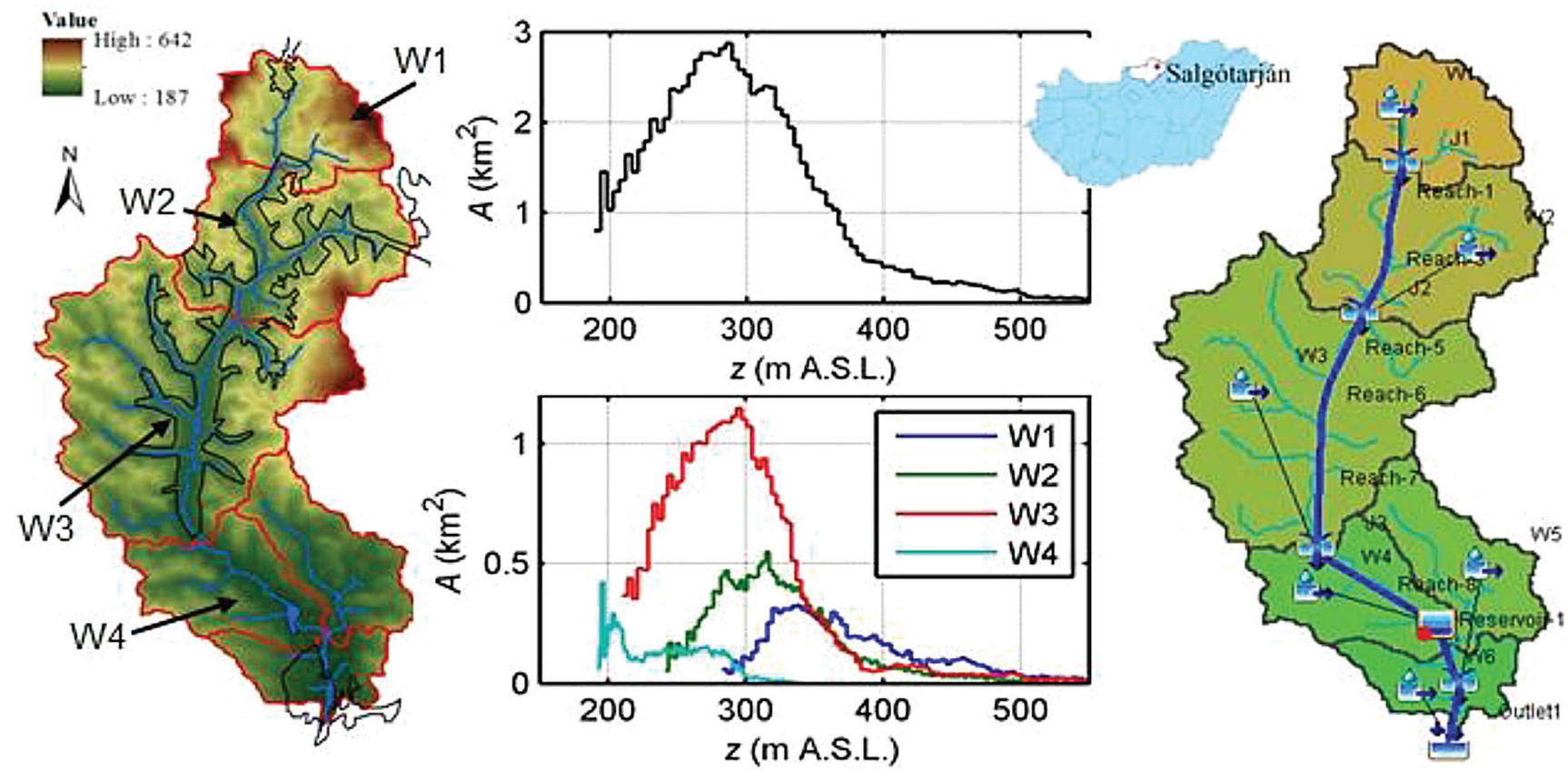

Fig. 1: Left: DEM of the Tarján Creek watershed. Middle: elevation profiles of the whole basin and the subwatersheds above the outlet. Right: the HEC-HMS model. 
Tab. 2: Statistical measures of the calibration and the validation for the reservoir inflow

\begin{tabular}{|l|cc|cc|}
\hline \multirow{2}{*}{ Statistical measure } & \multicolumn{2}{|c|}{ Calibration } & \multicolumn{2}{c|}{ Validation } \\
\cline { 2 - 4 } Average runoff $\left(\mathrm{m}^{3} / \mathrm{s}\right)$ & Modelled & Observed & Modelled & 0.83 \\
Peak discharge $\left(\mathrm{m}^{3} / \mathrm{s}\right)$ & 1.18 & 1.22 & 4.2 & 3.7 \\
Standard deviation of runoff $\left(\mathrm{m}^{3} / \mathrm{s}\right)$ & 7.5 & 7.4 & 0.77 & 0.94 \\
Correlation & 0.93 & & 1.04 & 1.09 \\
Relative root mean square error $(\%)$ & & 0.78 & & 0.77 \\
Nash-Sutcliffe parameter $(-)$ & & 3.10 & & 0.96 \\
\hline
\end{tabular}

to evaluate the different time of concentration equations, additional parameters were required. A complete list of the parameters calculated from the digital elevation model is in the Appendix. The curve numbers $(\mathrm{CN})$ were selected based on the available land use and soil maps. According to our estimations: $\mathrm{CN}$ values are 80 and 65 , roughness coefficients $(n)$ are 0.15 and 0.3 for inhabited and forested areas, respectively. Considering the ratio of this two land use on each subwatershed, we obtained that $\mathrm{CNs}$ are 66,$70 ; 68$ and 65 while the maximum retention capacities $\left(S_{c s c}\right)$ are 130,109, 120 and 137 for the W1, W2, W3 and W4 subwatershed, respectively.

\section{HYDROLOGICAL MODELLING}

\subsection{Model set up}

The HEC-HMS (USACE, 2013) numerical model was selected to evaluate the rainfall-runoff processes in the Tarján Creek watershed. In this model, the hydrological elements can be connected in a network that imitates the watershed's hydrological components. The meteorological component is the first step and uses rainfall as an input. In the next step, the rainfall which contacts pervious surfaces is subject to losses (interception, infiltration, evaporation and transpiration) and is modelled by a rainfall loss component. The effective
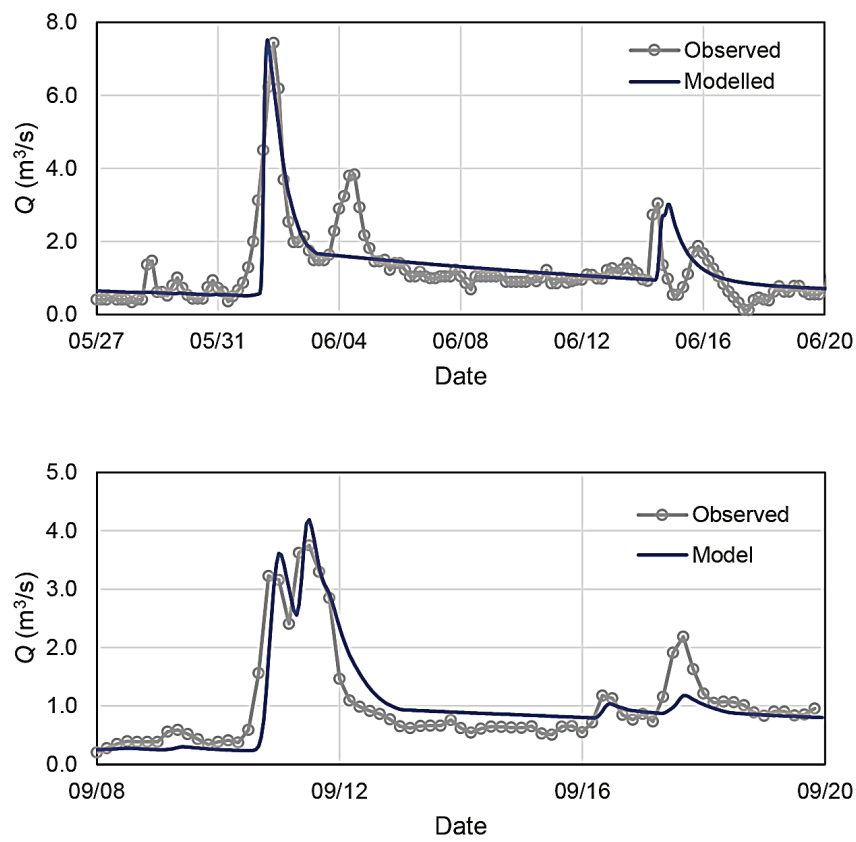

rainfall from the loss component contributes to the direct runoff. The loss component was calculated using the deficit and constant method, which uses only one single soil layer to model the moisture content. The constant rate specifies the infiltration rate when the soil is saturated, while the maximum storage defines the amount of water that the soil can contain. Rainfall from impervious surfaces is not subject to losses and instantly enters the direct runoff component, where it is transformed into overland flow. The Clark unit hydrograph (UH) method was used for modelling the surface flow. The aquifer water movements were modelled by the baseflow component. The recession baseflow model was used. Both the overland flow and baseflow enter the creek channels (HEC, 2000). The translation and attenuation of the streamflow in the creek is simulated by the river routing component; the Muskingum-Cunge method was used (Cunge et al, 1980).

\subsection{Calibration and validation}

During the event-based calibration, the model was primarily fitted to the pool's elevation and secondarily to the inflow to the reservoir, since it was not possible to use the stream flow data directly. Six parameters had to be calibrated, as such, the initial deficit, the maximum storage and the constant rate of the loss component; the recession constant and the ratio-to-peak parameter of the baseflow component; and the $T_{C}$ in the Clark UH. The inflow data into the reservoir was
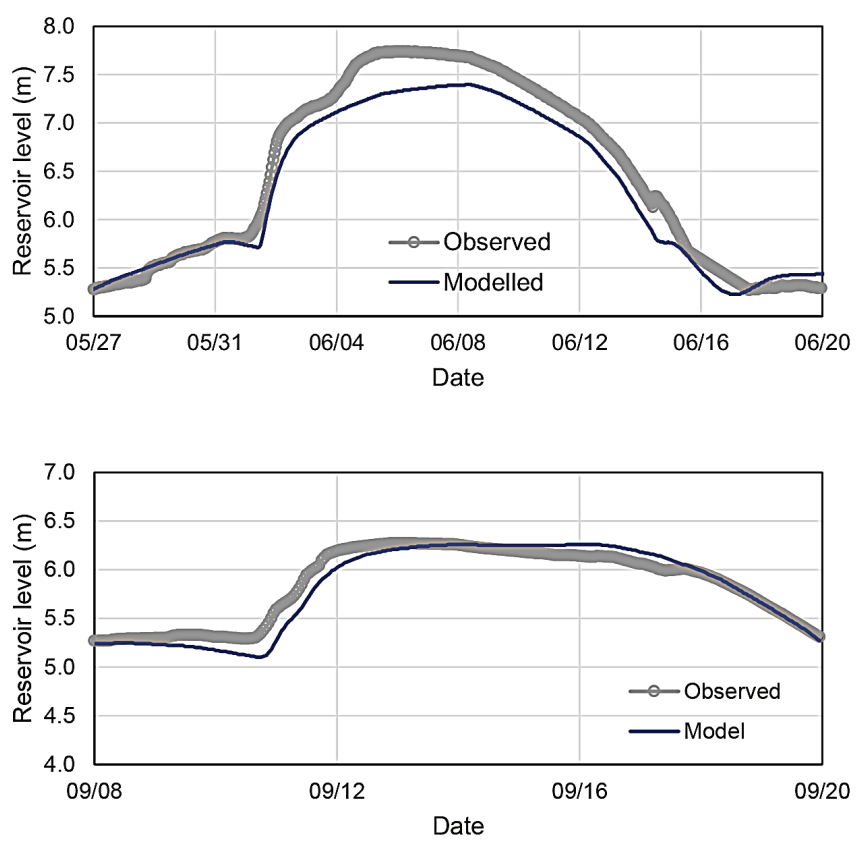

Fig. 2: Results of the model calibration (upper) and validation (lower) for the reservoir inflow (left) and reservoir water level (right). 
determined by a water balance equation using the reservoir's stage storage curve and measured stream flow $1 \mathrm{~km}$ downstream. A uniform flow was assumed in the $1 \mathrm{~km}$ downstream channel between the reservoir and the stream gauge. The outflow structure of the reservoir is a sluice gate. Its opening is manually adjusted to reduce, increase, or maintain the reservoir level elevations. The results of the water balance calculations were extremely sensitive to the choice of timestep; therefore, the calculated stream flow into the reservoir required constant checking to insure that the flow and storage were physically reasonable. The direct runoff was calculated by the Clark UH method, which requires the $T_{c s u b}$ for each subwatershed. As an initial guess, $T_{c, s u b}$ were determined with the Wisnovszky equation (see Appendix). Since runoff data are only available at the outlet of the W4 watershed, the $T_{c \text { sub }}$ of the subwatersheds were varied together in a trial-and-error fashion during the calibration, but the ratio between them was constant throughout. Table 2 shows the statistical performance measures selected for the evaluation of the model.

The largest flood hydrograph was selected for calibration from the 2010 time series data. For the validation, another 2010 flood wave was selected. The largest flood hydrograph occurred in the spring, while the hydrograph selected for the validation occurred in the fall. Figure 2 shows the graphic comparison between the HMS model's results and the reservoir inflows and elevations measured for the calibration and validation.

\section{ESTIMATION OF THE TIME OF CONCENTRATION}

A number of timing parameters are commonly used with hydrological and hydraulic models, including the time of concentration, lag time, and reach travel time. Time parameters are usually defined with the watershed's characteristics or with the relationship between the excess rainfall and direct runoff (Grimaldi et al. 2012, McCuen 2009, Fang et al. 2005). Following $T_{c}$, the second most used parameter is the basin lag time $T_{L}$. It is often defined as the difference between the centroid of the excess rainfall to the centroid of the mass of the direct runoff (Viessman and Lewis, 2003). These two parameters are often related where the lag time is about $60 \%$ of $T$ (USACE 2013). From a computational point of view, there are many definitions in technical use, especially for $T_{L}$. A graphic summary of the different definitions is given in Figure 3. If simultaneous rainfall and runoff measurements are available, the computational definitions for $T_{c}$ are: (I) the time from the end of the excess rainfall to the inflection point of the falling limb of the total runoff hydrograph; (Ia) the time from the centroid of the excess rainfall to the inflection point. The basin lag time is most commonly stated as (II) the time from the centroid of the excess rainfall to the centroid of the direct runoff. We note here that we have found many other definitions for it as shown in Figure 3.

In the case of ungauged basins, $T_{c}$ can be estimated using the following methodologies: (a) estimation through empirical formulas; (b) estimation based on formulas that include flow velocity and distinguish the overland and the channel flow; and (c) estimation by means of hydrodynamic models with different complexities. Although method (c) is the most physically-based, the results are highly sensitive to the resolution of the DEM used and Manning's roughness coefficients. The most common methods for estimating the time of concentration are methods (a) and (b). In the technical literature, several empirical equations can be found, while in Hungary only one equation is in practical use, i.e., the Wisnovszky equation. A total of 29 equations were collected from the literature, 14 of which met our applicability criteria. Those 14 were then used for estimating $T_{c, s u b}$ on the Tarján creek's subwatersheds. The application criteria are usually based on the size and typical slope conditions of the watershed.

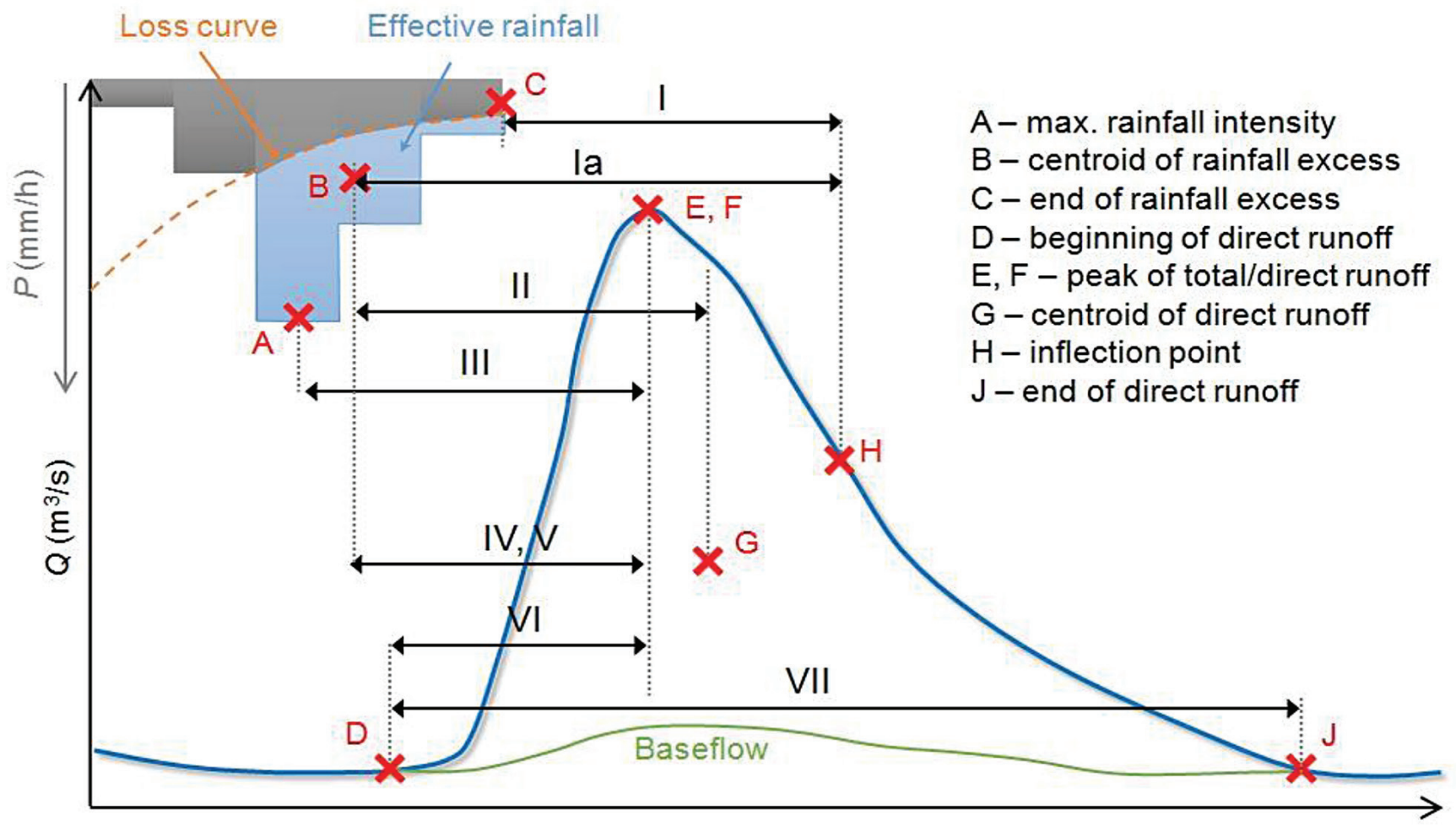

Time

Fig. 3: Interpretation of different time parameters based on specific points of the hyetograph and hydrograph. I, Ia - Time of concentration; II, III, IV, V - lag time; VI - time to peak, VII - time base of the runoff. 


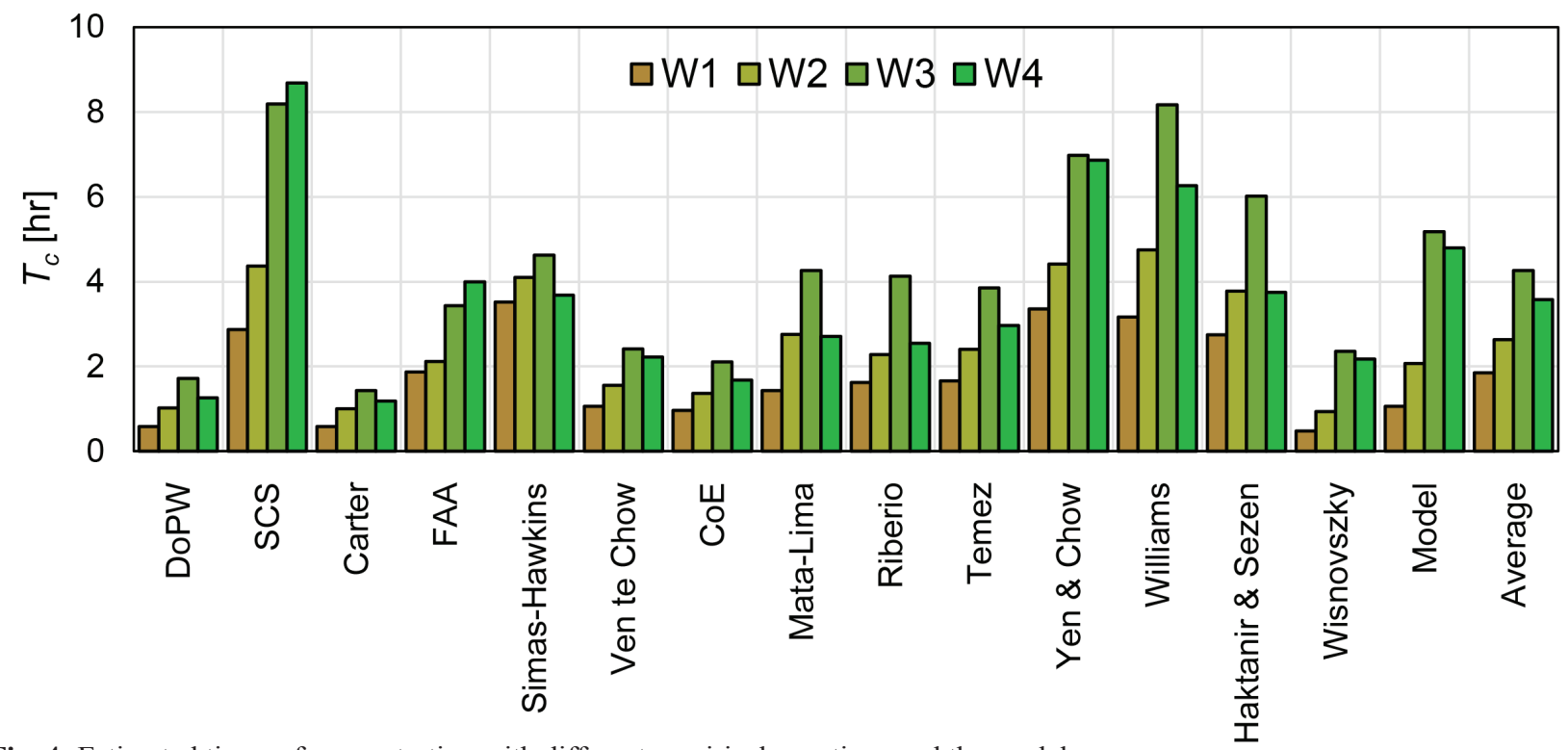

Fig. 4: Estimated times of concentration with different empirical equations and the model.

The empirical formulas were evaluated for the four subwatersheds. Their morphological parameters were determined as described in Section 2.1. The equations are summarised in the Appendix, while the calculated $T_{c}$ values are shown in Figure 4. The estimated $T$ were compared to the calibrated $T_{c}$ values using the HEC-HMS model and the mean of the $T$ estimations. They are shown in Figure 4 as well. The averages are very close to those obtained by the model. The Wisnovszky equation, the most commonly applied formula in Hungary, resulted in a $50 \%$ underestimation of $T$ for each subwatershed.

The results reflect the watershed's characteristics. W1 is the smallest and steepest watershed, resulting in the smallest $T_{c}$. The trend is similar for all four watersheds; with decreasing slopes, $T$ increases, except for the W3 watershed, which has the largest watershed area, main channel and the longest hydraulic length (Table 1). The two exceptions are the SCS and the FAA equations, which contain information about the soil and land use parameters (the curve number $(\mathrm{CN})$ and the runoff coefficient) in addition to the morphological specifications. Relative to the average, four methods (DoPW, Carter, Chow, and CoE) under-predicted $T_{c}$, by $50 \%$. Three methods (SCS, Yen, and Williams) over-predicted $T_{c}$ by more than $50 \%$.

The parameters calculated by the empirical formulas vary over a wide range. In order to see the effect of $T_{c}$, on the runoff hydrograph, we substituted the highest (SCS) and lowest (Carter) rates into the calibrated HEC-HMS model. The calibrated model was used as a base for the comparison. The resulting total runoffs are shown in Figure 5. As expected, peak flow significantly increases as $T_{c}$ decreases.
The SCS method, with 50 to $150 \%$ larger $T_{c}$ estimates, generated a $50 \%$ smaller peak flow, and the time to the peak increased as well. The Carter model underestimated $T$ by $40 \%-80 \%$, causing the peak discharge to increase significantly.

Comparing the empirical rates with the ones modelled, the formulas of FAA, Simas-Hawkins, Mata-Lima, Riberio, Temez, and Haktanir-Sezen may be used in practice. The latter has performed well for Texas watersheds according to the study of Fang et al. (2005).

\section{CONCLUSION}

The time of concentration of a watershed is an important parameter for hydrologists. Its value is influenced by many factors. The physical factors as well as the analytical assumptions in the empirical formulation lead to wide variations in its determination. Fortunately, in most cases $T_{c}$ shows a slightly asymptotic behaviour with an increasing peak discharge, so a reasonable value can be assigned to it, thereby leading to a conservative approximation for design purposes. Naturally, the authors did not expect that a universal formula can be created for Hungarian watersheds, but the most commonly used equation does need revision. Based on the results obtained, we have begun similar calculations for a dozen small and medium-sized watersheds in the north Hungarian mountains for which simultaneous rainfall-runoff data are available for the past decade. The analysis of timing parameters as a function of discharge and seasonality is also proposed.

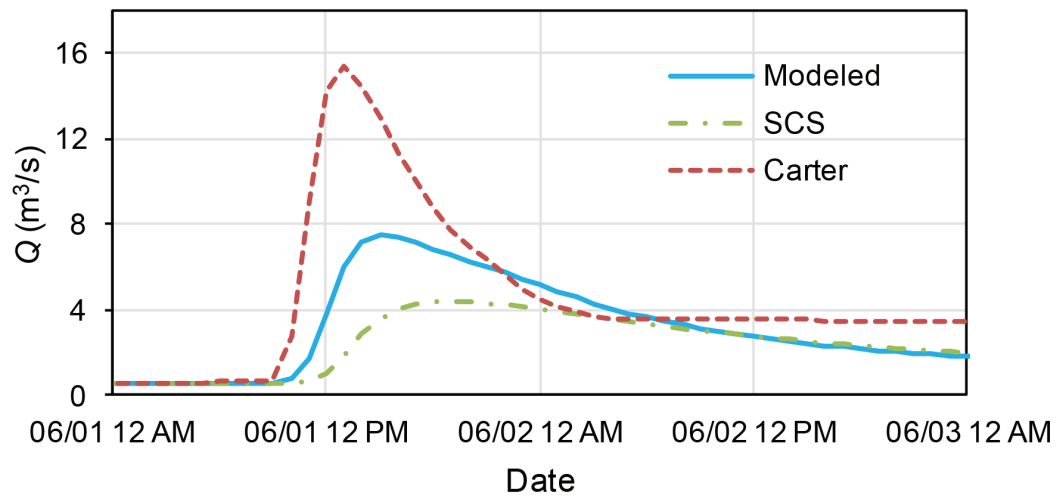

Fig. 5: Change in runoff due to changes of $T_{c}$ in the model. 


\section{REFERENCES}

Bene, K. - Torma, P. - Keve, G. - Hajnal, G. (2015) "Impact of climate change on the Eger Creek Watershed", In: Gribovszki, Z., Hlavčová, K., Kalicz, P., Kohnová, S., and Carr G. (eds.) HydroCarpath-2015, Catchment processes in regional hydrology: Linking experiments and modelling in Carpathian drainage basins. Vienna, Austria, Oct. 29, 2015

Cunge, J. A. - Holly, F. M. Jr. - Verwey A. (1980) Practical Aspects of Computational River Hydraulics. Pitman, London.

Fang, X. - Asquith, W. H. - Garcia, C. A. - Cleveland, T. G. Thompson, D. - Malla, R. (2005) "Literature review on timing parameters for hydrographs", Project Report 0-4696-1, Dept. of Civil Eng., Lamar University, Beaumont, TX.

Grimaldi, S. - Petroselli, A. - Tauro, F. - Porfiri, M. (2012) "Time of concentration: a paradox in modern hydrology", Hydrological Sciences Journal, 57(2), pp. 217-228.

HEC (2000) Technical Reference Manual, Hydrologic Modelling System HEC-HMS, Hydrologic Engineering Center, US Army Corps of Engineering
Koch, R. - Bene, K. (2013) "Continuous Hydrologic Modelling with HMS in the Aggtelek Karst Region”, Hydrology, 1(1), pp:1-7.

McCuen, R. H. (2009) "Uncertainity analyses of watershed time parameters", Journal of Hydrologic Engineering, 14(5), pp. 490498.

Soroosh, S. - Seyed, M. (2011) "Methodology for Identifying the Best Equations for Estimating the Time of Concentration of Watersheds in a Particular Region" Journal of Irrigation and Drainage, 137(11), pp. 712-719.

Torma, P. - Széles, B. - Hajnal, G. (2014) "Applicability of different hydrological model concepts on small catchments: case study of Bükkös Creek, Hungary", Acta Silv. Lign. Hung., 10(1), pp. 77-90, DOI: 10.2478/aslh-2014-0006.

USACE (2013): User's Manual version 4, Hydrologic Modelling System HEC-HMS, Hydrologic Engineering Center, US Army Corps of Engineering

Viessman, Jr. W. - Lewis, G. L. (2003) Introduction to Hydrology, Pearson Education, Inc., USA 


\section{APPENDIX}

List of equations for time of concentration estimation

\begin{tabular}{|c|c|c|c|c|}
\hline Name & Equation & Drainage area & Slope & Character. \\
\hline $\begin{array}{l}\text { Dept. of Public Works } \\
\text { (1995) }\end{array}$ & $T_{C}=60 \cdot\left(\frac{11,9 \cdot L^{3}}{H}\right)^{0,385}$ & Small & - & Mountainous \\
\hline SCS (1972) & $T_{C}=0,0526 \cdot\left(\frac{1000}{C N}-9\right)^{0,7} \cdot L^{0,8} \cdot S^{-0,5}$ & Small & - & Mountainous \\
\hline Carter (1961) & $T_{C}=100 \cdot L_{m}^{0,6} \cdot S_{m}^{-0,3}$ & - & - & $\begin{array}{l}\text { Natural channel, } \\
\text { partly drained }\end{array}$ \\
\hline Fed. Aviation Adm. (1970) & $T_{C}=1,8 \cdot(1,1-C) \cdot \frac{L^{0,5}}{S^{0.333}}$ & - & - & - \\
\hline Simas-Hawkins (2002), & $T_{C}=0,322 \cdot A^{0,594} \cdot L_{w}{ }^{-0,59} \cdot S^{-0,150} \cdot S_{S C S}{ }^{0,313}$ & $0,001-14 \mathrm{~km}^{2}$ & - & - \\
\hline Ven Te Chow (1962) & $T_{C}=0,1602 \cdot L_{w}^{0,64} \cdot S^{-0,32}$ & $0,01-18,5 \mathrm{~km}^{2}$ & $0,5-9 \%$ & - \\
\hline Corps of Eng. (2005) & $T_{C}=0,191 \cdot L_{w}^{0,7} \cdot S^{-0,19}$ & $<12000 \mathrm{~km}^{2}$ & - & - \\
\hline Mata-Lima et al (2007) & $T_{C}=4 \cdot A^{0,5} \cdot L_{w}^{0,5} \cdot H_{m}^{-0,5}$ & - & - & Rural \\
\hline Riberio (1960) & $T_{C}=0,267 \cdot(1,05-0,2 \cdot p)^{-1} \cdot L_{w} \cdot S^{-0,04}$ & $<19000 \mathrm{~km}^{2}$ & $3-10 \%$ & - \\
\hline Temez (1978) & $T_{C}=0,3 \cdot\left(\frac{L_{w}}{S^{0,25}}\right)^{0,76}$ & - & - & Natural \\
\hline Yen and Chow (1983) & $T_{C}=1,2 \cdot\left(\frac{n \cdot L_{w}}{S^{0,5}}\right)^{0,6}$ & - & - & - \\
\hline Williams (1922) & $T_{C}=\frac{0,272 \cdot L_{w} \cdot A^{0,4}}{D \cdot S^{0,2}}$ & $<129,5 \mathrm{~km}^{2}$ & - & - \\
\hline Haktanir\&Sezen (1990) & $T_{C}=0,7473 \cdot L_{w}^{0,841}$ & $11-9867 \mathrm{~km}^{2}$ & - & - \\
\hline Wisnovszky (1958) & $T_{C}=\frac{L_{v}{ }^{2}}{\sqrt{A \cdot S}}$ & - & - & - \\
\hline
\end{tabular}

Notation: $L$ - max. distance between outlet and divide [ft, miles or km], $L_{o}-$ length of overland flow [ft], $L_{w}-$ length of main water line [km], $L_{m}$ - longest channel length [miles], $L_{v}$ - length of valley [km], $H$ - max difference in elevation between the outlet and divide [ft], $H_{m}$ - elevation between the ends of the main water line [m], $S$ - basin slope [ft/mi, or m/km], $S_{m}$ - slope of the longest channel [ft/mile], $A-$ area $\left[\mathrm{km}^{2}\right], D$ - equivalent diameter of the watershed [km], $C N$ - curve number [-], $S_{C S C}$ - max. capacitiy of retention [mm], $p-$ ratio of the vegetation-covered area [-], $C$-rational method runoff coefficient [-], $n$ - Manning's roughness coefficient $\left[\mathrm{s} / \mathrm{m}^{1 / 3}\right]$. 